\title{
Desbordes de lo humano: configuraciones del cuerpo en María Luisa Bombal y Diamela Eltit.
}

\section{The Overflows of the Humankind: the Configuration of the Body in the Literary Works of Maria Luisa Bombal and Diamela Eltit.}

\section{Resumen}

El presente artículo compara la construcción de representaciones corporales femeninas en dos novelas de escritoras chilenas que atraviesan el siglo XX: La amortajada (1938) de María Luisa Bombal y Lumpérica (1983) de Diamela Eltit. La exposición se organiza en torno a la pregunta por el modo a través del cual las autoras exploran los límites de lo humano y lo nohumano y de qué manera se inscriben y polemizan con los mandatos en torno a la producción simbólica de una corporalidad normativa. La hipótesis que estructura el trabajo sostiene que las autoras elaboran un posicionamiento crítico respecto de las formulaciones de lo comunitario, lo humano y la subjetividad que se inscriben en la materialidad del cuerpo femenino.

Palabras claves

María Luisa Bombal, Diamela Eltit, Cuerpo, Disidencia.

\begin{abstract}
The article compares the construction of the female body representations in two novels of Chilean writers who go through the 20th century: La amortajada (1938) by Maria Luisa Bombal, and Lumpérica (1983) by Diamel Eltit. The exposition is organized around a question due to the manner in which both authors explore the limits of the human and the non-human, and the way those limits are inscribed and debated with the orders around the symbolic production of a normative corporeality. The hypothesis of this work holds that the authors present a critical stance towards the development of the nation, the community, the humankind and the subjectivity, which are inscribed on the materiality of the female body..
\end{abstract}

Keywords 


\section{Introducción}

A fines de la década del 30, la escena literaria chilena y latinoamericana se ve profundamente sorprendida por la irrupción de la figura de María Luisa Bombal, escritora nacida en Viña Del Mar y educada en París. Tanto la publicación de La última niebla (1935) como de La amortajada (1939) señalan un punto de corte respecto de la estética de los escritores criollistas ${ }^{1}$ y dan cuenta de un cuidadoso trabajo de experimentación técnica y temática de inspiración surrealista (el lirismo de la prosa y la exploración del inconsciente, principalmente). En su segunda novela, la originalidad de la escritora se revela como una transgresión al explorar, a la manera de un continuum existencial, el universo posmortem: la protagonista (y principal voz narradora) se ubica en su lecho de muerte y, desde ahí, reconstruye los principales acontecimientos de su vida y describe el tránsito hacia la tumba como un llamado de la naturaleza.

Algunas décadas después, a comienzos de los 80, la aparición de Lumpérica (1983), primera novela de la escritora y artista visual Diamela Eltit, marca un hito en el escenario artístico posterior al Golpe de Estado de 1973 (Cánovas 2009). En efecto, el texto se inscribe dentro de las urgencias coyunturales de las décadas del 60 y el 70 en el Cono Sur en las que los distintos movimientos artísticos exploran permanente técnicas que combinan vanguardia e internacionalismo como estrategias de modernización y de rearticulación de lo estético y lo político en escenarios particularmente represivos. Eltit participa del proyecto de la neovanguardia que, en la búsqueda de nuevos lenguajes orientados a la desarticulación de la lengua de los opresores, tiende a la construcción de dispositivos que imponen la idea de la discontinuidad y de la fragmentación

\footnotetext{
${ }^{1}$ La noción de "Criollismo" ha recibido múltiples y muy variados tratos en la crítica literaria latinoamericana. En este caso, junto con Lucía Guerra, utilizo esta denominación para referirme a la continuidad de estéticas propias del siglo XIX en la narrativa de comienzos del siglo XX que combinan elementos propios del naturalismo y el realismo con estructuras axiológicas fuertemente vinculadas con los procesos de fundación de imaginarios nacionales. De allí la gravitación de términos como telurismo o novela de la tierra para referirse a este período.
} 
CATEDRAL TOMADA: Revista de crítica literaria latinoamericana / Journal of Latin American Literary Criticism Desbordes de lo humano: configuraciones del cuerpo en María Luisa Bombal y Diamela Eltit.

(Richard, Insubordinación 7)². Así, en Lumpérica el cuerpo de su protagonista, L. Iluminada, se constituye en un territorio en el que se yuxtaponen discursos e imágenes de un lenguaje en deconstrucción y escenifica un devenir animal como desterritorialización extrema de un orden social autoritario (Solorza 2015).

Si bien es cierto que las propuestas estéticas de María Luisa Bombal y de Diamela Eltit, con una gran distancia temporal entre sí, difieren en la articulación del lenguaje (la exploración de las fronteras entre lirismo y prosa, por un lado, frente a la deconstrucción de las leyes gramaticales y puesta en tensión de la capacidad referencial de la lengua, por el otro) y en las configuración de las imágenes de lo comunitario y lo amoroso, las protagonistas de sus novelas se constituyen como sujetos que intervienen de manera crítica sobre los imaginarios vinculados con lo femenino e instauran interrogaciones que ponen de relieve los mandatos que se tejen en torno a la corporalidad humana, especialmente la femenina. En relación con esto y con el tratamiento que ambas autoras han recibido por parte de la crítica literaria, Rubí Carreño Bolívar señala una paradoja por cuanto si bien Bombal y Eltit ocupan un lugar central dentro del canon literario del siglo XX, su pertenencia a la "patria literaria" no ha sido un proceso fácil ni inmediato (Carreño, Leche 16). El espacio de estas narraciones, desde la perspectiva de Carreño Bolívar, configura metáforas que dan cuenta no sólo de un cuidadoso trabajo con el lenguaje sino que señalan las tensiones y contradicciones del orden social y las diferencias sobre las que este se erige.

\footnotetext{
${ }^{2}$ Nelly Richard señala de qué manera opera en las prácticas estéticas del período una necesidad de escindir los relatos hegemónicos e introducir fisuras dentro de las construcciones históricas legitimadas por las instituciones del Estado dictatorial. Asimismo, plantea la necesidad de reformular las categorías con las que se piensa el "arte militante" ante la experiencia de la crisis que se inicia con la experiencia de la violencia: "La ruptura nació del desafío de tener que darles nombre a fracciones de experiencia que ya no eran verbalizables en el idioma que sobrevivió a la catástrofe de sentido. Por un lado, estaba la lengua de la impostura hablada por el poder oficial. Por otro lado, estaban el molde ideológico del arte militante de la cultura partidaria y el discurso de las ciencias sociales cuyo formato de investigación buscaba encuadrar las poéticas de la crisis en el marco explicativo de un racionalismo demasiado ajeno a la remecida de los sentidos desatada por el trance referencial. Ninguno de esos dos lenguajes era lo bastante sensible a las conmociones de signos que habían estremecido la máquina de representación social" (Richard, Insubordinación 7).
} 
Es por ello que, atendiendo a la centralidad que adquieren las representaciones del cuerpo en los textos de ambas autoras, en el presente artículo me propongo analizar cuáles son las modalidades a través de las que los textos exploran los límites entre lo humano y lo no humano, por un lado, y de qué manera estos se constituyen como dispositivos de interpelación estética y política en relación con la coyuntura en la que se inscriben, por otro. Entiendo, al respecto, que una de las principales consecuencias de la cultura sobre las subjetividades es la delimitación de la materia que nos conforma, es decir la delimitación del cuerpo y sus funciones para desplegar sobre él el conjunto de creencias, hábitos y prácticas que constituyen la noción de civilidad.

En este sentido, considero que las imágenes de los cuerpos presentados en ambas novelas pueden ser leídas como una red de citas en las que se reescribe y se politiza un amplio conjunto de discursos referidos al campo literario y cultural. Así, a partir de la noción de "cosmopolitanismo disidente" [dissident cosmopolitanism] (Garrido y Giorgi 2015), sostengo que las autoras elaboran un posicionamiento crítico respecto del modo en que los discursos de lo comunitario se inscriben en el cuerpo femenino. Así, al posicionar las narraciones desde las imágenes de cuerpos anómalos, en devenir animal o entre fronteras (posortem) los textos ensayan estrategias de resistencia y socavamiento de las lógicas culturales de la dominación en las sociedades contemporáneas. De esto se desprende una conceptualización del cuerpo como una materialidad significante a través del cual se exhiben los dispositivos políticos y las series históricas que lo producen y lo transforman (Giorgi Cuerpo 209).

Organizo mi exposición a partir de una pregunta de carácter teórico, ¿Qué puede un cuerpo?, para señalar algunas formulaciones acerca de la articulación entre prácticas culturales, corporalidad, subjetividad y comunidad. En segundo lugar, me aboco al análisis de las representaciones corporales en las novelas seleccionadas haciendo especial hincapié en las implicancias estéticas y políticas de la exploración de los límites entre lo humano y lo no humano. Por último, presento algunas reflexiones finales que se desprenden del análisis. 
CATEDRAL TomadA: Revista de crítica literaria latinoamericana / Journal of Latin American Literary Criticism Desbordes de lo humano: configuraciones del cuerpo en María Luisa Bombal y Diamela Eltit.

\section{¿Qué puede un cuerpo?}

La palabra cuerpo presenta en el español una serie de matices semánticos de gran interés para pensar las prácticas culturales y los procesos de subjetivación. En primer lugar, la física utiliza esté término para designar a una determinada porción de materia que se caracteriza por poseer una delimitación y un peso específicos. Es decir, un cuerpo se entiende como una diferencia respecto de un conjunto. En el plano de la anatomía, la palabra se utiliza para designar al agrupamiento de órganos que definen a la fisonomía humana o animal. Asimismo, en el marco de los estudios del discurso, por vía de una extensión metafórica se suele hablar de corpus para referirse a una serie de piezas textuales en las que se distingue una regularidad y una especifidad respecto del universo total de producciones discursivas. A partir de este breve recorrido por las relaciones semánticas entre estos términos es posible señalar de qué manera en el acto de habla que se ejecuta al referirse a la palabra "cuerpo" se designa no solo a una porción de materia sino que, a la vez, se la delimita e identifica.

En este orden de reflexiones, ser un cuerpo, desde una perspectiva cultural vinculada con los estudios de género específicamente ${ }^{3}$, implica significar funciones naturales en relación con tecnologías y series históricas de adaptación al ambiente. Así, puede ser conceptualizado como una superficie que exhibe los dispositivos históricos y las series que lo producen y lo transforman: "[...] El cuerpo es el resultado de historias específicas y de tecnologías políticas que constantemente problematizan su estatuto y su lugar en el mundo social, en el orden cultural y en el dominio de lo natural" (Giorgi, Cuerpo 68). En este sentido,

${ }^{3}$ Con esta afirmación me refiero al pensamiento de Judith Butler quien toma distancia de las conceptualizaciones esencialistas del cuerpo y lo define como una performance, es decir un conjunto de prácticas inscriptas por el orden social y cultural. El cuerpo, para la autora, no es una superficie natural que expresa un conjunto de atributos inscriptos en su superficie de forma pasiva. (Butler 2003; Martínez 2011). 
las representaciones de lo corporal en las prácticas culturales dan cuenta de constelaciones históricas vinculadas con diseños políticos y economías del poder.

En relación con esta conceptualización, considero que las prácticas culturales y literarias se presentan como dispositivos políticos a través de los cuales

[...] se modulan múltiples distribuciones de lo que afecta a nuestros mundos sensibles, un espacio privilegiado en el cual se ensayan formas posibles (probables e improbables) de la vida en común y en donde, como consecuencia, se estrenan constantemente nuevas relaciones entre los cuerpos. (Arnés 9-10)

En lo que se refiere a la potencialidad política y estética de las representaciones del cuerpo, conviene señalar que este se inscribe en una tensión dialéctica entre el orden de lo clasificatorio, los lenguajes dominantes y el sentido común, por un lado; y la fuerza disruptiva del lenguaje y el deseo, por otro (Giorgi, Cuerpo 69). Es por ello que en el presente trabajo, al analizar las representaciones corporales femeninas en la narrativa de Bombal y Eltit, me propongo señalar cuáles son los deslizamientos de sentido que proponen las autoras y cuáles son las implicancias estéticas y políticas de ello.

En relación con esto, Germán Garrido y Gabriel Giorgi dan cuenta de cómo las escritoras latinoamericanas del siglo $\mathrm{XX}$ ponen en juego "cosmpolitanismos disidentes" [dissident cosmopolitanism] como estrategia para formular prácticas estético- políticas que interpelan a las agendas, de corte patriarcal, del modernismo/ modernización tradicionalmente asociadas al liberalismo y a las élites nacionales. La noción de "cosmpolitanismos disidentes" se entiende como un "deseo de mundo", es decir, la posibilidad de producir

${ }^{4}$ Los autores toman esta expresión de Mariano Siskind quien define al "deseo de mundo" [Cosmopolitan desire] como una de las estrategias a través de la cual distintos autores latinoamericanos producen y exploran representaciones de lo global a través de la relación con las heterogeneidades culturales, raciales y sexuales. El objetivo del autor es leer la modernidad latinoamericana como una relación global, inserta en una red transcultural de intercambios, 
CATEDRAL TOMADA: Revista de crítica literaria latinoamericana / Journal of Latin American Literary Criticism Desbordes de lo humano: configuraciones del cuerpo en María Luisa Bombal y Diamela Eltit.

imágenes en las que se combinan sexualidad, disidencia y perspectivas alternativas sobre lo comunitario (Garrido y Giorgi).

Desde este punto de vista, el nomadismo es la figura que mejor define la experiencia del cosmopolitanismo a través de una doble desterritorialización: de los cuerpos y de las subjetividades definidas por patrones de género, raza y clase. Además, a partir del cuestionamiento sobre la articulación de comunidad y subjetividad se deriva una problematización acerca de los límites de lo humano. Las novelas que analizo en el presente artículo elaboran posicionamientos que introducen una ruptura múltiple no solo respecto de las formaciones intelectuales identificadas con las estéticas hegemónicas sino que también se permiten explorar el devenir del cuerpo en la proyección de espacios y metamorfosis que se desplazan del plano de lo humano hacia lo viviente en un sentido amplio. En el caso de La amortajada la principal narradora habita un cuerpo que se posiciona en la frontera entre la vida y la muerte entendiendo a esta última no como una clausura del ciclo vital sino como instancia de transición hacia otros estadios de contacto y fusión con el plano de la naturaleza (la tierra, las raíces, la humedad) mientras que Lumpérica pone en escena un cuerpo, en devenir, arrasado por las tecnologías del poder que se resiste a ingresar dentro de las lógicas y gramáticas del autoritarismo.

En este orden de reflexiones, la exploración de la producción simbólica vinculada con los territorios de lo viviente no humano tiene larga tradición en la literatura latinoamericana ${ }^{5}$ y, de acuerdo con Giorgi (Animal), la emergencia de

deshaciendo una idea particularista de la diferencia cultural. Garrido y Giorgi, por su parte, efectúan un desplazamiento teórico- metodológico sobre esta noción por cuanto no se focalizan en las narrativas de "escritores viajeros" sino que se proponen recorrer los fluidos del género y las políticas sexuales. En consecuencia, el ejercicio estético de ampliación de fronteras no se remite solamente a nociones geográficas o del canon literario sino que implica también la indagación sobre los límites hacia el interior de la cultura.

5 Una de las ficciones fundacionales, en este sentido, es El Matadero (1873) de Esteban Echeverría en el que las imágenes del pueblo federal se yuxtaponen y se fusionan con restos de animales y aves carroñeras. La literatura de fines del siglo XIX y comienzos del XX da cuenta, también, de una tensión estructural entre sujeto y naturaleza en la que se pone en funcionamiento una axiología vinculada con la construcción del orden social de los estados contemporáneos. Entre este conjunto de ficciones aparecen novelas como Doña Bárbara (1929) de Rómulo Gallegos, 
representaciones dislocadas e irreductibles de las múltiples formas de vida se constituye en índice de una crisis en el pensamiento humanista y en la imaginación política. Lo animal, para el autor, se constituye en un material de amplia exploración estética y epistemológica por cuanto permite trazar imágenes alternativas de lo común por fuera de las determinaciones que hacen a la idea de civilización:

De nuevo el animal exterior, salvaje, el animal que provenía de la naturaleza exterior, del universo salvaje que asedió la imaginación moderna sudamericana gira sobre sí mismo y se vuelve un interior problemático como una inmanencia que transforma un orden de representación de cuerpos.

En ello se juega algo más que una nueva topografía de los cuerpos. No se trata solamente de que lo salvaje se haya extinguido en la imaginación cultural, de que la potencia de su amenaza y el fulgor de sus promesas se hayan atenuado al ritmo del control sobre la naturaleza que a mediados del siglo XX ya parecía, en líneas generales, cumplimentada. Tampoco se trata de que el animal doméstico o domesticado se haya convertido en la metáfora o alegoría obvia del control político, en sociedades que estaban perfeccionando los mecanismos de normalización social y las tecnologías del poder disciplinario. Se trata, sin duda, de todo eso, pero sobre todo se trata de algo más: esa vuelta interior del animal. Esa interiorización del animal refiere la emergencia de una nueva zona de problematización estética, que es también un nuevo terreno de politización [...]. (Giorgi, Animal 185)

La Vorágine (1924) de José Eustasio Rivera o los cuentos de Horacio Quiroga. No obstante, Giorgi (Animal) señala la aparición a partir de 1960 en el Cono Sur de un conjunto de ficciones que dan cuenta de un desplazamiento en las imágenes y en las políticas de lo animal como síntoma de una crisis biopolítica. Ubica dentro de este grupo a textos como A apixão segundo G.H. (1964) de Clarice Lispector y Meu tio o iaguarté (1960) de João Guimarães Rosa. La serie se complementa en la contemporaneidad con textos como Tadeys (1983) de Osvaldo Lamborghini, Salón de belleza (1995) de Mario Bellatin y Dame pelota (2008) de Dalia Rosetti, entre otros. 
En coincidencia con lo señalado por el autor, considero que tanto Bombal como Eltit elaboran una política de los cuerpos que pone en discusión las construcciones del sentido común a través de múltiples estrategias de extrañamiento. Como he señalado más arriba, en la novela de Bombal la exploración del cuerpo humano se identifica, primero, como una transgresión al orden de la existencia y, luego, como fusión con la naturaleza. La novela de Eltit, por su parte, representa el cuerpo de su protagonista a través de múltiples yuxtaposiciones y dislocamientos técnicos que dan cuenta de "[...] la violencia desestructuradora de un paisaje hecho de trozos y de destrozo" (Richard, Prólogo 11). La escritura practica una demarcación de la subjetividad por vía de constantes desterritorializaciones. En ese recorrido, el devenir yegua o vaca de L. Iluminada constituye una exploración estética y una política que propende a la interrogación permanente de los símbolos asociados a la experiencia de una modernización autoritaria y excluyente.

\section{María Luisa Bombal: el reflujo de las superficies vitales}

Cae la noche en un asentamiento rural de una región indeterminada de Chile y en una de sus casas un acontecimiento particular reúne a familiares, vecinos y amigos: el velorio de Ana María, una mujer que ha sido hija, esposa, suegra, hermana y amante. Como es esperable en este tipo de rituales, acuden a la casa un conjunto de personas que han tenido gran influencia en su trayecto vital: su esposo, sus hijos, su nuera, el amor de su infancia y su padre. Sin embargo, Ana María, envuelta en su mortaja, abre los ojos para mirar a las personas que la rodean, oye sus voces, siente y recuerda su vida. A través de un juego entre múltiples perspectivas narrativas la enunciación se instala en el espacio- tiempo de la muerte para hilvanar fragmentos y repeticiones que hacen a la historia de la 
protagonista y, a su vez, dan cuenta del tránsito del cuerpo que cede ante un llamado de la naturaleza. En efecto, a lo largo de la novela el cuerpo de la protagonista se manifiesta como una unidad diferenciada del orden de lo humano:

Comprende que en el espacio inasible de un minuto inasible ha cambiado su ser. Que al levantar Fernando los ojos había hallado a una estatua de cera en el lugar en que yacía la mujer codiciada.

Cuantos entran al cuarto se mueven ahora tranquilos, se mueven indiferentes a ese cuerpo de mujer, lívido y remoto, cuya carne parece hecha de otra materia que la de ellos. (Bombal, Amortajada 81)

Este cuerpo-otro se constituye en un dispositivo a través del cual se refractan un conjunto de prácticas y saberes en torno a los rituales amorosos, a la sociabilidad femenina y a lo religioso. A lo largo de la novela este proceso se articula a la manera de una crisis epistemológica por cuanto la protagonista en su nuevo estado asume el rol de sujeto que interpela los discursos de quienes la circundan y acompañan en su tránsito hacia el sepulcro. No es casual, en este sentido, que cuando el narrador en tercera persona se refiere a Ana María utiliza con alta frecuencia verbos de carácter cognitivo tales como "comprender", “entender", "recordar" o "distinguir". Asimismo, a través del estilo indirecto libre la palabra de Ana María hace uso de un conjunto de preguntas retóricas que se orientan a reflexionar acerca del amor y de los significados asociados a la muerte. Uno de los temas centrales de esta reflexión se refiere a los afectos y señala de qué manera en la construcción subjetiva del personaje opera una tensión entre el exceso y el límite. Desde mi punto de vista, dicha tensión puede ser interpretada como un elemento residual de la configuración estética del amor romántico de la novela siglo XIX. Así, por ejemplo, en la primera parte de la novela Ricardo, el primer amor de Ana María, la visita en su lecho mortuorio y ella recuerda todo el proceso de enamoramiento: 
Ahora comprende también que en el corazón y en los sentidos de aquel hombre ella había hincado sus raíces; que jamás, aunque a menudo lo creyera, estuvo enteramente sola; que jamás, aunque a menudo lo pensara, fue realmente olvidada... ¡Ah, Dios mío, Dios mío! ¿Es preciso morir para saber? (Bombal, Amortajada 44- 45)

Asimismo, haciendo un repaso por su vida familiar y por la "educación sentimental" recibida, el discurso de Ana María pone en evidencia nuevamente la tensión entre el exceso y el límite en el ejercicio de los afectos:

¡Curioso esto de haber tenido que portarse así con los seres que ella más amó! Con Antonio, con sus hijos.

“Hay que ser juiciosa en el amor”, solía aconsejarse a sí misma. Y había logrado en efecto muy a menudo ser juiciosa. Había logrado adaptar su propio vehemente amor al amor mediocre y limitado de los otros...Porque el no amarlos demasiado sea tal vez la mejor prueba de amor que se pueda dar a ciertos seres, en ciertas ocasiones. ¿Es que todos los que han nacido para amar viven así como ella vivió? ¿Ahogando minuto a minuto lo más vital dentro de sí? (Bombal, Amortajada 105)

Por otra parte, como he mencionado más arriba, la novela se articula alrededor de una crisis de carácter epistemológico en la que interpela a distintas esferas sociales y su producción de conocimientos. Precisamente, uno de los campos discursivos con los que debate la enunciación de la protagonista es el de las creencias de la religión católica acerca de la muerte y la producción de subjetividades "culpables" o "castigadas":

“-Alicia, mi pobre hermana, ¡eres tú! ¡Rezas!” 
¿Dónde creerás que estoy? ¿Rindiendo cuentas al Dios terrible a quien ofreces día a día la brutalidad de tu marido, el incendio de tus aserraderos y hasta la pérdida de tu único hijo, aquel niño desobediente y risueño que un árbol arrolló al caer y cuyo cuerpo se dislocó entero cuando lo levantaron de entre el fango y la hojarasca?

Alicia, no. Estoy aquí, disgregándome bien apegada a la tierra. Y me pregunto si veré algún día la cara de tu Dios. (Bombal, Amortajada 4950)

Frente a la idea de ascenso o trascendencia del alma que propugna el discurso de la fe católica apostólica romana respecto de la muerte, la novela propone un trayecto centrado en la experiencia corporal que estrecha sus vinculaciones con el ámbito de la naturaleza. El cuerpo de Ana María transita hacia un encuentro con las superficies vitales del mundo, con la tierra, con lo húmedo y con las raíces que son asimiladas a la cabellera humana e insinúa la idea de una continuidad de los ciclos más que de una clausura y separación entre materia y espíritu. Además, atendiendo a los argumentos que he presentado más arriba, es posible afirmar que el texto impugna la noción de castigo y culpa a favor de una imagen cíclica de los procesos vitales. Cito a modo de ejemplo un fragmento del final del texto:

Una vez más, la amortajada refluyó a la superficie de la vida.

En la oscuridad de la cripta tuvo la impresión de que podía moverse... Pero nacidas de su cuerpo, sentía una infinidad de raíces hundirse y esparcirse en la tierra como una pujante telaraña por la que subía temblando, hasta ella, la constante palpitación del universo.

Y ya no deseaba sino quedarse crucificada a la tierra, sufriendo y gozando en su carne el ir y venir de lejanas, muy lejanas mareas; sintiendo crecer la hierba, emerger islas nuevas y abrirse en otro 
CATEDRAL TOMADA: Revista de crítica literaria latinoamericana / Journal of Latin American Literary Criticism

Desbordes de lo humano: configuraciones del cuerpo en María Luisa Bombal y Diamela Eltit.

continente la flor ignorada que no vive sino un día de eclipse. Y sintiendo aún bullir y estallar soles, y derrumbarse, quién sabe dónde, montañas gigantes de arena. (Bombal, Amortajada 142- 143)

\section{Diamela Eltit: la cosa que ha llegado a ser.}

Lumpérica (2008) instala a sus personajes en el tiempo de una noche que dilata el amanecer a lo largo de todo el texto como una promesa que no termina de llegar. El escenario en el que se despliegan las acciones es el de una plaza pública en medio del paisaje de la moderna ciudad de Santiago cuyo régimen visual está gobernado por un cartel que recibe la designación de "el luminoso". Al comienzo del texto la protagonista, L. Iluminada, permanece de espaldas sobre el cemento alcanzada por la luz artificial de los faroles mientras espera recibir el bautismo de parte del cartel que preside el espacio. Pero ella no es la única bautizada puesto que se identifica con una colectividad de sujetos:

Llegan los desharrapados de Santiago, pálidos y malolientes a buscar su área: el nombre y el apodo que como ficha les autorizará un recorrido, pero normado por el gasto previo de la carne hasta que calcen por luz con el luminoso.

Así serán nombrados genéricamente pálidos como escalafón provisorio. Esos que vienen desde los puntos más distantes de la plaza que prendida por redes eléctricas garantiza una ficción de ciudad. (Eltit 15)

El texto propone, así, una mirada que articula la idea de una “identificación ciudadana" como producción de subjetividades en relación con el ordenamiento del espacio físico y la discriminación de roles sociales (bautismo). Adela Rolón señala, al respecto, que el escenario de la plaza encuentra una 
referencia cultural en el ágora griega, lugar en el que nace la democracia, pero que en este caso lo que se representa es una teatralización irónica de la patria en la que impera el desamparo frente al control y el mandato de un sujeto omnipotente y omnipresente como el que simboliza el luminoso. Por su parte, Megan Corbin destaca que la novela elabora un giro en torno a corporalidades abyectas y vidas marginadas que obligan al lector a enfrentar la existencia caótica y sangrienta de la ciudadanía dictatorial. Por mi parte, desde la perspectiva de Michel Foucault, considero que la idea de conformación ciudadana y civilización se manifiesta en el texto como ejercicio regulador y disciplinador de las subjetividades en tanto potencialidades críticas y subversivas. En relación con esto es importante recordar que, como señale al comienzo del trabajo, la aparición de esta novela en 1983 se presenta como un punto de quiebre respecto de la producción cultural en el marco particular de la dictadura de Augusto Pinochet (1973- 1990) e introduce un conjunto de experimentaciones técnicas en la construcción de una estética de resistencia.

En efecto, como en un juego barroco la complejidad del texto se revela no solo en el plano temático sino en la yuxtaposición de planos y materiales que multiplican los puntos de vista y hacen proliferar distintas versiones de los acontecimientos sin que ninguna prevalezca ${ }^{6}$. Cada uno de los capítulos de la novela se construye a través de una articulación múltiple entre géneros discursivos: la narración, el ensayo, el guion cinematográfico y la teatralización del proceso de escritura y representación ${ }^{7}$.

A lo largo de toda la novela el cuerpo de L. Iluminada se presenta como un signo complejo y en permanente mutación a través del cual se inscriben tanto

${ }^{6}$ Kemy Oyarzún conceptualiza del siguiente modo a la escritura de Eltit: "He aquí el cuerpo textual: un movimiento que interrumpe los flujos del capital, que solaza paródicamente, irónicamente, en el tintineo feroz de los intercambios sexuales y los tráficos verbales: las sedimentaciones de distintos dispositivos de poder se van develando en tanto lenguaje, en tanto tecnologías discursivas, en tanto materiales y soportes estético- políticos" (Oyarzún 144).

${ }^{7}$ Megan Corbin caracteriza al lenguaje narrativo de la autora como barroco por cuanto interpela al lector a ingresar en el proceso de gestación de la escritura, descifrar códigos anormales y construir sentidos múltiples a partir de enunciados fragmentarios ubicándose desde el cuerpo como escenario de operaciones. 
los mandatos del luminoso como las estrategias de subversión a estos lenguajes por medio de movimientos dislocados que interpelan a la comunidad de la plaza. En este entramado de mutaciones, en el capítulo tercero el texto escenifica un nacimiento/ devenir animal de la protagonista como una conjunción metafórica con las imágenes de una yegua y de una vaca. La estética interpela tanto dese el erotismo plástico de los movimientos de la yegua en un desafío erótico a la comunidad de la plaza, como en el mugido de la vaca que quiebra con cualquier estetización banal a la vez que se manifiesta como un lenguaje inarticulado:

Se queja en tonos que cunden la rajadura de su aura, tiñen más bien el puncetear de aguerridas ramas sus receptáculos...se arrastra y deja su baba tendida a la par de los caminos de la plaza/ marca un recorrido.

Raja su aura de nefasto augurio y todavía mantiene intacta la feroz incidencia de su garganta. Perturba al que la oye en tan sonados trotes o tropelías que se condiciona...Algo ha pasado que su tono baja, la vaca se recoge en sus marginaciones, la yegua se sosiega, la cosa que ha llegado a ser se detiene de pleno para que la arboleda tan ruin en su realeza salte a primeros planos. (69-70)

La imagen del devenir animal se presenta como una operación alegórica que conecta la idea de una exploración y reivindicación de la experiencia corporal a la vez que elabora una imagen de la experimentación de las prácticas artísticas y literarias en relación con las fuerzas del mercado y de la política. El tránsito hacia la experiencia de lo animal se manifiesta como desterritorialización del lenguaje y de las prácticas asociadas con la producción reguladora de subjetividades ciudadanas en la coyuntura particular en la que se escribe la novela. En este sentido, considero que la imagen animal en Eltit permite trazar un perfil acerca de su poética y elabora una crítica hacia las lógicas de consumo y circulación de la producción cultural en el marco de la experiencia neoliberal y autoritaria de la dictadura. Así, el cuerpo nómade se revela como una estrategia desestabilizadora 
de los lenguajes disciplinatorios: "Está la yegua suelta y sus pelos brillan de forma peligrosa, más que dañarse, daño puede hacer contra la plaza si no organiza con razón su huella" (Eltit 76).

\section{Conclusiones}

En este trabajo me he propuesto analizar de qué manera cada una de las autoras referidas, María Luisa Bombal y Diamela Eltit, exploran las fronteras de la corporalidad humana en sus experimentaciones narrativas. Para ello he partido de una serie de presupuestos conceptuales que entienden al cuerpo no solo como una determinada porción de materia sino como una unidad construida social, política y culturalmente. Asimismo, al conceptualizar las prácticas literarias como un espacio privilegiado en el que se ensayan formas posibles de la vida en común (Arnés 10), considero que las imágenes de los cuerpos que se despliegan tanto en La amortajada como en Lumpérica pueden ser leídas como una red de citas en las que se reescribe y se politiza un amplio conjunto de discursos referidos al campo literario y cultural.

En el caso la novela de Bombal, la imagen del cuerpo que se construye impugna un amplio espectro de discursos y prácticas vinculadas con el plano de los afectos, la existencia y la fe. Este cuerpo-otro explora la conciencia de la vida en la comunidad desde una perspectiva posmortem que se resignifica en el texto como un camino de encuentro con la naturaleza, con lo viviente esencial. La enunciación de su protagonista se desliga de cualquier discursividad moralizante o de lamento y pone de relieve el flujo de las superficies vitales que conectan el cuerpo con lo terrenal. Al respecto del impacto de esta novela en el campo literario de su época y de las referencias extratextuales con las que dialoga es conveniente señalar que mientras que en el criollismo (referente literario hegemónico) y en su contrapartida, el Surrealismo, replegaban a las mujeres al 
CATEDRAL Tomada: Revista de crítica literaria latinoamericana / Journal of Latin American Literary Criticism Desbordes de lo humano: configuraciones del cuerpo en María Luisa Bombal y Diamela Eltit.

papel de naturaleza y del misticismo desde una perspectiva patriarcal, Bombal (en coincidencia con otras mujeres artistas como Frida Khalo, Leonora Carrington y Remedios Varo), elabora un espacio propio en el que la corporalidad femenina es escenario de problemas y empoderamientos sexuales, estéticos y políticos (Guerra 1997; Carreño Bolívar 2007).

Por otro lado, Lumpérica se presenta como la escenificación de un conjunto de alegorías vinculadas con la producción simbólica del terror y su impacto en la construcción de subjetividades e identificaciones ciudadanas. El cuerpo de su protagonista, L. Iluminada, se presenta como un signo complejo y en permanente mutación a través del cual se inscriben tanto los mandatos del luminoso como las estrategias de subversión a estos lenguajes por medio de movimientos dislocados que interpelan a la comunidad de la plaza. Esta tensión se constituye en una imagen que sintetiza la idea de "arte refractario" elaborada por Nelly Richard, es decir, el gesto de construir piezas que al interior de sí mismas generan zonas de resistencia en las que se aloja algo inintegrable al orden (Richard Márgenes). Así, el cuerpo de L. Iluminada se ofrece como una alegoría que puede tanto representar a la patria asediada por el terror y por el mercado pero también como a la propia escritura. En este sentido, el devenir animal se manifiesta como una desterritorialización del lenguaje y de las prácticas asociadas con la producción reguladora de subjetividades ciudadanas como estrategia que impugna tanto el orden dictatorial como las lógicas del campo y la producción de imaginarios afines al poder de turno.

Por último, una de las categorías centrales de este trabajo ha sido la de "cosmpolitanismos disidentes" [dissident cosmopolitanism] entendida como un amplio abanico de estrategias a través de las cuales las escritoras latinoamericanas formulan prácticas estético- políticas que interpelan a las agendas, de corte patriarcal, de la experiencia moderna en la región y de los imaginarios en torno a la producción simbólica de nuestras sociedades. Desde este punto de vista, el nomadismo como idea que atraviesa a esta categoría me ha permitido señalar una doble desterritorialización en los textos analizados: de los cuerpos y de las 
subjetividades definidas por patrones de género y clase. En otras palabras, las autoras construyen cuerpos entre fronteras que permiten dar cuenta de exploraciones alternativas de las prácticas y regímenes culturales a partir de experiencias de exclusión y violencia. El cuerpo que se pone de manifiesto en estos textos se inscriben en una tensión no resuelta entre las sociedades de control (Foucault 2014) y su afuera, desmarcado.

\section{Bibliografía}

Arnés, Laura. Ficciones lesbianas. Literatura y afectos en la cultura argentina. Buenos Aires: Madreselva, 2016.

Bombal, María Luisa. La amortajada. Buenos Aires: Andina, 1971.

Bombal, María Luisa. Obras completas. Lucía Guerra, editora. Santiago: Editorial Andrés Bello, 1997.

Butler, Judith. El género en disputa. El feminismo y la subversión de la identidad. Barcelona: Paidós, 2007.

Cánovas, Rodrigo. (2009). "Diamela Eltit. Algunos años antes, algunos años después". Diamela Eltit: redes locales, redes globales. Rubí Carreño Bolívar, editora. Santiago: Iberoamericana, 2009. 25- 32.

Carreño Bolívar, Rubí. Leche amarga: violencia y erotismo en la narrativa chilena del siglo XX (Bombal, Brunet, Donoso, Eltit). Santiago: Cuarto Propio, 2007.

---. (ed).Diamela Eltit: redes locales, redes globales. Santiago: Iberoamericana, 2009. 
CATEDRAL TOMADA: Revista de crítica literaria latinoamericana / Journal of Latin American Literary Criticism Desbordes de lo humano: configuraciones del cuerpo en María Luisa Bombal y Diamela Eltit.

---. “¿Qué eres? Una torpe, alerta, alarmada, pasafronteras”. Diamela Eltit: redes locales, redes globales. Rubí Carreño Bolívar, editora. Santiago: Iberoamericana, 2009. 13- 21.

Corbin, Megan. "Archiveras anarquistas: Corporal Testimony i the Work of Diamela Eltit". Catedral tomada: Revista de crítica literaria latinoamericana 1/1 (2013): 1-17. http://catedraltomada.pitt.edu/ojs/index.php/catedraltomada/article/view/29 4 de julio de 2017.

Domínguez Romero, Noelia. "Decir con el cuerpo. La resignificación del sujeto femenino en La amortajada de María Luisa Bombal". A contracorriente: una revista de historia social y literatura 9/ 3 (2012): 67- 93.

https://acontracorriente.chass.ncsu.edu/index.php lacontracorriente/article/view/294 4 de julio de 2017.

Eltit, Diamela. Lumpérica. Sabtiago: Seix Barral, 2008.

Foucault, Michel. Vigilar y castigar. Buenos Aires: Siglo XXI, 2014.

Giorgi, Gabriel y German Garrido. "Disident cosmpolitanisms". The Cambridge History of Latin american Women's Literature. Ileana Rodríguez y Mónica Szurmuk, editoras. Cambridge; Cambridge UP, 2015. 1- 26.

Giorgi, Gabriel. "Cuerpo". Diccionario de estudios culturales latinoamericanos.

Mónica Szurmuk y Robert Mckee Irwin, coordinadores. México: Siglo

XXI e Instituto Mora, 2009. 67- 71.

Giorgi, Gabriel. "El "animal de adentro": retóricas y políticas de lo viviente". Voz y escritura. Revista de Estudios Literarios 20 (2012): 181- 194.

Giorgi, Gabriel. “Especies especiales”. Suplemento Soy, Página 12 (2015).

https://www.pagina12.com.ar/diario/suplementos/soy/1-3950-2015-04-

24.html 21 de abril de 2017.

Guerra, Lucía. “Introducción”. Obras completas de María Luisa Bombal. Lucía

Guerra, editora. Santiago: Editorial Andrés Bello, 1997. 7- 49. 
Martínez, Ariel. “Los cuerpos del sistema sexo/género: Aportes teóricos de Judith Butler”. Revista de Psicología 12 (2012): 127-144.

Orozco Vera, María Jesús. "La narrativa de María Luisa Bombal: principales claves temáticas". Cauce: revistas de Filología y su didáctica 12 (1989): 39- 56.

Oyarzún, Kemy. “Corruptos por la impresión: vigencia de Lumpérica hoy”. Diamela Eltit: redes locales, redes globales. Santiago: Iberoamericana, 2009. 133- 145.

Richard, Nelly. La insubordinación de los signos (Cambio político, transformaciones culturales y poéticas de la crisis). Santiago: Cuarto Propio, 1994.

Richard, Nelly. Márgenes e instituciones. Arte en Chile desde 1973. Santiago: Metales Pesados, 2007.

Richard, Nelly. "Prólogo". Lumpérica. Diamela Eltit. Santiago: Seix Barral, 2008. 7- 11.

Rolón, Adela. "Estrategias por la vida. Lumpérica de Diamela Eltit”. De jóvenes escritores para nuevos lectores. Estela Saint André y Adela Rolón, coordinadoras. San Juan: EFFHA. 30- 40.

Siskind, Mariano. Deseos cosmopolitas: Modernidad global y literature mundial en América Latina. México: CFE, 2016.

Solorza, Paula Susana. "Cuerpos en fuga: el devenir minoritario del lenguaje en Lumpérica y Los vigilantes de Diamela Eltit”. Nomadías 20 (2015): 27- 40. 